\title{
ANTROPOMETRI SENDI PERGELANGAN TANGAN PADA ETNIS MINANGKABAU
}

\author{
Daldy Arianda ${ }^{1}$, Roni Eka Sahputra ${ }^{1}$, Sylvia Rachman², Erkadius ${ }^{3}$
}

\begin{abstract}
Abstrak
Penatalaksanaan fraktur distal radius adalah mengembalikan kekuatan menggenggam serta mempertahankan biomekanik sendi pergelangan tangan, sehingga pasien dapat mengerjakan aktifitas seperti sediakala, serta mengurangi resiko penyakit degeneratif di kemudian hari. Rentang gerak sendi juga merupakan bagian dari penilaian keselarasan anatomi, namun sedikit didiskusikan dalam kepustakaan. Penelitian ini bertujuan menilai antropometri sendi pergelangan tangan etnis Minangkabau. Survey analitik cross sectional dilakukan pada 50 mahasiswa kedokteran pria dan wanita beretnis Minangkabau, usia 21- 25 tahun. Data dianálisis untuk mengetahui nilai mean, standar deviasi serta menguji perbedaan antropometri pria dan wanita menggunakan $t$ - test independen dengan derajat kepercayaan $95 \%$. Nilai mean dan simpang deviasi ukuran ROM palmarfleksi 79,22 \pm 9,58; dorsofleksi 72,22 \pm 10,54; ulnar deviasi 40,74 \pm 9,43; radial deviasi 24,68 4 4,92; radial inclination 24,02 $\pm 3,49 ;$ Radial length 11,35 \pm 1,56; Palmar Tilt $12,27 \pm 6,12$. Terdapat perbedaan nilai radial inclination antara pria dan wanita $(p=0,001)$. Penelitian ini menyimpulkan terdapat perbedaan bermakna secara statistik radial inclination pria dan wanita mahasiswa kedokteran yang beretnis Minangkabau. Selain itu terdapat perbedaan antropometri antara penelitian ini dengan kepustakaan yang lazim.
\end{abstract}

Kata Kunci : Antropometri, Minangkabau.

\begin{abstract}
As it is known that the treatment of distal radius fractures is to restore the biomechanical strength of grip and maintain joint movement of the wrist so that the patient can do normal activities, and reduce the risk of degenerative diseases of the joints of the wrist in the future. From various journals and literature more votes just only on morphometry, while the range of motion is also part of conformity assessment anatomy as well. This study aimed to measure anthropometric of wrist joint of Minangkabau ethnic group. This study used cross sectional analytical survey on medical students, men and women, with Minangkabau ethnic group, age 21- 25 years, with a sample size of 50 people. Data was analysed to determine the mean and standard deviation, and to examine difference in male and female anthropometric measurement by using an independent t-test with a 95\% degree of confidence. Result : Mean and standar deviation value ROM palmarfleksi $79.22+$ 9.58; dorsiflexion $72.22+10.54$; ulnar deviation of $40.74+9.43$; radial deviation of $24.68+4.92$. The size of the radial inclination was $24.02+3.49$. Radial length was $11.35+1.56$. Tilt Palmar size was $12.27+6.12$. Statistically there was significant difference of radial inclination between women and men ( $p=0.001)$. Conclusion: There were significant differences in the average value of the radial inclination between men and women of Minangkabau ethnic group. Besides, there were some differences in anthropometric measurement in this study compared to figure commonly reported in literature.
\end{abstract}

Keywords: Antropometric, minangkabau.

Afiliasi Penulis: 1. Bagian IImu Bedah FK Unand/ RSUP Dr. M.Djamil, 2. Bagian Radiologi FK Unand/ RSUP Dr. M.Djamil, 3. Bagian Fisiologi FK Unand Padang. Korespondensi: Daldy Arianda, Bagian Bedah FK Unand/ RSUP Dr. M.Djamil, Padang. Email: daldyarianda@gmail.com Telp +6281348051215 


\section{PENDAHULUAN}

Bangsa Indonesia adalah bangsa yang multikultural. Hal ini terlihat dari keberagaman masyarakat Indonesia yang majemuk baik dari suku/etnis, agama, ras maupun kelompok sosial yang ada dalam masyarakat itu sendiri. Kemajemukan dalam masyarakat Indonesia ini diungkapkan oleh seorang ahli sosial budaya, "Clifford Geetz" yang mengatakan bahwa Indonesia adalah negara dengan multi etnis yang sedemikian kompleks sehingga sulit melukiskan anatominya secara persis. $^{1}$

Pengamatan sehari-hari akan membawa kita kepada pengalaman bahwa manusia, walaupun satu spesies, bervariasi juga. Kenyataan ini mendorong orang untuk melihat perbedaan-perbedaan ini dengan makin teliti. Metode yang paling tepat untuk ini adalah dalam bentuk ukuran, di samping ketepatan juga untuk objektivitas. ${ }^{2}$

Antropometri adalah suatu studi yang berkaitan dengan dimensi tubuh manusia. Bidang antropometri meliputi berbagai ukuran tubuh manusia seperti berat badan, posisi, rentang tangan, rentang sendi, dan sebagainya. Manusia memiliki berbagai ukuran tubuh yang berbeda antara yang satu dengan yang lainnya. ${ }^{3}$ Dari penelitian yang pernah dilakukan pada sendi lutut dapat disimpulkan bahwa terdapat ukuran sendi lutut yang khas dan bervariasi pada populasi etnis Sunda, dengan nilai standar yang lebih tinggi terutama dalam hal variasi tibial posterior slope. ${ }^{4}$ Dalam penelitian lain disebutkan juga perbedaan bermakna sudut anteversi leher femur populasi Indonesia dengan populasi India. ${ }^{5}$ Dari gambaran penelitian di atas, ternyata etnis atau suku bangsa ber- pengaruh pada ukuran anatomi manusia sehingga dari sini peneliti ingin mengetahui bagaimana antropometri distal radius pada populasi etnis Minangkabau di Padang, Sumatera Barat. Dengan demikian untuk mengetahui tingkat keberhasilan dalam penanganan fraktur distal radius pada etnis Minangkabau khususnya di Sumatera Barat dapat menggunakan nilai antropometri tersendiri. Sehingga prinsip penanganan fraktur yang meliputi reduksi, imobilisasi dan pengembalian fungsi serta kekuatan normal dapat terwujud dengan baik. ${ }^{6}$

Seperti diketahui bahwa penatalaksanaan fraktur distal radius adalah mengembalikan kekuatan menggenggam dan gerakan sendi pergelangan tangan sehingga pasien dapat mengerjakan aktifitas seperti sediakala sesuai dengan waktu yang diharapkan dan mengurangi resiko penyakit degeneratif di kemudian hari. ${ }^{7}$ Dari berbagai jurnal, penilaian lebih banyak pada morfometri saja (radial inclination, palmar tilt, dan radial length)..$^{8,9,10,11,12}$, sementara rentang gerak sendi juga merupakan bagian dari penilaian keselarasan anatomi setelah tindakan. ${ }^{6}$ Oleh karena itu, pemahaman mengenai batasan normal morfometri distal radius menjadi sangat penting dalam manajemen fraktur distal radius untuk mempertahankan keselarasan anatomi. 8,9

Dari berbagai literatur penanganan yang sudah dilakukan di negara-negara barat dengan subjek penelitian terutama bangsa kulit putih, didapatkan data tentang nilai-nilai normal pemeriksaan radiologis distal radiusdan rentang geraksendi yang dapat digunakan sebagai pedoman untuk memperkirakan keberhasilan setelah tindakan reposisi. Disini disebutkan bahwa nilai normal radial 
inclination rata-rata $22^{\circ}$, radial length 12 $\mathrm{mm}$, dan radial tilt 110.13,14 Pada literatur lain disebutkan nilai normal palmar tilt rata-rata $11^{0}\left(1^{0}-23^{0}\right)$, radial tilt $15^{0}-30^{0}$ dan radial length $12 \mathrm{~mm} .{ }^{15}$ Dari literatur lain disebutkan pula radial tilt $12^{\circ}$, radial inclination rata-rata $20^{\circ}$ dan palmar tilt $11^{0}-12^{0} \cdot{ }^{16,17}$

Demikian pula untuk rentang gerak sendi pada pergelangan tangan disebutkan dorsofleksi (ekstensi) $75^{\circ}$, volarfleksi (fleksi) $75^{\circ}$, radial deviation $20^{\circ}$, dan ulnar deviation $35^{0} .{ }^{18}$ Dalam literatur lain di sebutkan ekstensi $0^{0}-60^{\circ}$, fleksi $0^{0}-60^{\circ}$, radial deviation $0^{0}-20^{\circ}$ dan ulnar deviation $0^{0}-30^{0} .{ }^{19}$ Berdasarkan nilai antropometri dari masing-masing literatur tersebut, ternyata ditemukan nilai yang bervariasi. Kemajemukan tersebut mungkin salah satunya dipengaruhi oleh perbedaan dari populasi sampel yang diambil.

Fraktur distal radius merupakan fraktur tersering pada tubuh manusia. Fraktur pergelangan tangan yang melibatkan distal radius ini memiliki prevalensi $8-15 \%$ dari fraktur ekstrimitas atas. Di Swedia lebih dari 20.000 pasien mengalami cedera ini. ${ }^{6}$ Di Rumah Sakit M. Djamil Padang terdapat 122 kasus yang mengalami fraktur distal radius selama Januari 2011 sampai dengan Juni 2012. Sudah banyak yang menulis tentang fraktur ini, namun masih banyak pertanyaan yang timbul tentang hasil yang diharapkan dan penanganan yang optimal. $^{7}$

Sejauh ini dalam praktek seharihari kita menggunakan parameter nilai normal antropometri distal radius dari literatur barat sebagai referensi untuk evaluasi nilai yang dapat diterima setelah tindakan. ${ }^{20}$ Nilai-nilai tersebut merupakan hasil dari penelitian yang dilakukan di negara-negara barat dengan subjek penelitian terutama bangsa kulit putih, yang secara fisik berbeda dengan populasi lokal Indonesia.Dengan demikian, hal ini kurang dapat memberikan gambaran mengenai nilai-nilai normal pada populasi lokal, sehingga data yang ada tidak dapat dijadikan nilai standar lokal khususnya pada populasi etnis Minangkabau di Padang, Sumatera Barat.

Melihat banyaknya manfaat yang bisa diperoleh dari pemeriksaan antropometri sendi pergelangan tangan yang dapat membantu evaluasi dan tata laksana fraktur distal radius, dan karena sampai saat ini penelitian antropometri tersebut pada etnis Minangkabau belum ditemukan dalam kepustakaan, maka peneliti bermaksud melakukan pengukuran nilai antropometri sendi pergelangan tangan normal pada populasi etnis Minangkabau di Padang, Sumatera Barat. Diharapkan agar dapat diperoleh suatu gambaran nilai antropometri normal sendi pergelangan tangan manusia pada populasi ini.

\section{METODE}

Penelitian ini dilakukan dalam lingkungan RS. Dr. M. Djamil dengan pemeriksaan radiologi di Bagian Radiologi RS Semen Padang. Penelitian dilakukan pada bulan Maret hingga Mei 2015. Penelitian ini merupakan penelitian survey analitik dengan menggunakan desain penelitian cross-sectional study.Populasi dalam penelitian ini adalah mahasiswa kedokteran pria dan wanita usia 21-25 tahun, etnis Minangkabau dalam lingkungan RSUP Dr. M. Djamil Padang bulan Maret hingga Mei 2015 yang memenuhi kriteria inklusi dan eksklusi. Pada penelitian ini akan digunakan sampel 50 orang. Data akan dianalisis untuk meng- 
hitung ukuran-ukuran statistik mean, standar deviasi dan standard error. Untuk menguji perbedaan Antara ukuran hasil penelitian antropometri pria dan wanita digunakan t-test independen dengan derajat kepercayaan 95\%. Kemaknaan hasil uji ditentukan oleh nilai $p<0,05$.

\section{HASIL DAN PEMBAHASAN}

Hasil penelitian diperoleh setelah dikumpulkan data dari pengukuran morfometri sendi pergelangan tangan dari foto rontgen posisi AP dan lateral, dan pemeriksaan rentang gerak sendi (ROM) pada sendi pergelangan tangan mahasiswa kedokteran di lingkungan RSUP Dr. M. Djamil padang di Instalasi radiologi RS Semen Padang pada bulan Maret 2015 Mei 2015. Besar sampel pada penelitian ini sebanyak 50 sampel dengan perincian 25 pria dan 25 wanita dengan kisaran usia 21 - 25 tahun yang memenuhi kriteria inklusi. Dimana pengukuran morfometri dengan menggunakan sistim komputerisasi dan pengukuran rentang gerak sendi dengan menggunakan alat goniometri. Data diolah dengan menggunakan program komputer.

\section{Tabel 1 : Distribusi frekuensi karakte-} ristik sampel penelitian

\begin{tabular}{ccc}
\hline & $\mathbf{N}$ & $\%$ \\
\hline Jenis kelamin & & \\
Pria & 25 & 50 \\
Wanita & 25 & 50 \\
Usia & & \\
21 tahun & 29 & 58 \\
22 tahun & 13 & 26 \\
23 tahun & 6 & 12 \\
24 tahun & 1 & 2 \\
25 tahun & 1 & 2 \\
\hline Total & 50 & 100 \\
\hline
\end{tabular}

Berdasarkan tabel 5.1 di atas, didapatkan jumlah sampel pria dan wani- ta sama yaitu sebanyak 25 orang (50\%). Berdasarkan usia, sampel terbanyak pada usia 21 tahun yaitu sebanyak 29 orang (58\%).

Tabel2: Distribusi palmarfleksi, dorsofleksi, ulnar deviasi, radial deviasi, radial inclination, radial lenght dan palmar tilt.

\begin{tabular}{lrrr}
\hline \multicolumn{1}{c}{ Parameter } & \multicolumn{1}{c}{ Mean } & \multicolumn{1}{c}{ SD } & \multicolumn{1}{c}{ SE } \\
\hline Palmarfleksi & 79.22 & 9.58 & 1.36 \\
Dorsofleksi & 72.22 & 10.54 & 1.49 \\
Ulnar Deviasi & 40.74 & 9.43 & 1.33 \\
Radial Deviasi & 24.68 & 4.92 & 0.70 \\
Radial Inclination & 24.02 & 3.49 & 0.49 \\
Radial Length & 11.35 & 1.56 & 0.22 \\
Palmar Tilt & 12.27 & 6.12 & 0.87 \\
\hline
\end{tabular}

Berdasarkan tabel 5.2 di atas, didapatkan ukuran ROM palmarfleksi $79,22 \pm 9,58$; dorsofleksi 72,22 \pm 10,54; ulnar deviasi 40,74 $\pm 9,43$; radial deviasi $24,68 \pm 4,92$. Ukuran radial inclination $24,02 \pm 3,49$. Ukuran Radial length 11,35 \pm 1,56. Ukuran Palmar Tilt 12,27 $\pm 6,12$.

Secara statistik penelitian menunjukkan perbedaan nilai rerata yang bermakna pada radial inclination antara pria dan wanita $(p<0,05)$. Sampel penelitian ini yang terdiri dari 25 pria dan 25 wanita berusia 21 tahun - 25 tahun, dengan demikian telah terjadi penutupan lempeng epífisis, namun belum terjadi erosi tulang $30,35,36$.

Selain itu dalam penelitian ini tangan yang dipakai sebagai subjek penelitian adalah yang tidak dominan dengan harapan proses erosi tulang akibat penggunaan tangan yang terus menerus dapat dikurangi walaupun proses erosi biasanya terjadi pada usia 25 tahun ke atas, sehingga bias dalam pengukuran di harapkan juga dapat berkurang. 
Tabel 3 : Perbedaan palmarfleksi, dorsofleksi, ulnar deviasi, radial deviasi, radial inclination, radial lenght dan palmar tilt antara pria dan wanita.

\begin{tabular}{lcrrrrr}
\hline \multicolumn{1}{c}{ Pemeriksaan } & \multicolumn{2}{c}{ Pria } & \multicolumn{2}{c}{ Wanita } & \multicolumn{1}{c}{ T } & $\mathbf{P}^{*}$ \\
\hline Palmarfleksi & Mean & \multicolumn{1}{c}{ SD } & Mean & \multicolumn{1}{c}{ SD } & & \\
Dorsofleksi & 78.32 & 9.51 & 80.12 & 9.77 & -0.660 & 0.512 \\
Ulnar Deviasi & 72.24 & 10.74 & 72.20 & 10.55 & 0.013 & 0.989 \\
Radial Deviasi & 42.68 & 10.32 & 38.80 & 8.21 & 1.472 & 0.148 \\
Radial Inclination & 25.64 & 4.92 & 23.72 & 4.82 & 1.394 & 0.170 \\
Radial Length & $\mathbf{2 2 . 4 6}$ & $\mathbf{2 . 5 7}$ & $\mathbf{2 5 . 5 8}$ & $\mathbf{3 . 6 4}$ & $\mathbf{- 3 . 5 0 7}$ & $\mathbf{0 . 0 0 1}$ \\
Palmar Tilt & 11.54 & 1.45 & 11.15 & 1.67 & 0.878 & 0.384 \\
\hline
\end{tabular}

*Analisis statistik: uji T-test independent

Subjek penelitian adalah mahasiswa kedokteran yang beretnis Minangkabau, dengan harapan dengan diambilnya mahasiswa kedokteran sebagai subjek penelitian akan dapat mengurangi variabel konfounding yang mempengaruhi dalam proses pertumbuhan tulang (dengan cara menghomogenkan sampel penelitian). Sementara itu yang dikatakan etnis Minangkabau dalam penelitian ini selain mengacu pada buku karya $A . A$. Navis (1984) ${ }^{40}$, juga di tambahkan bahwa bapak, ibu, kakek dan nenek pada subjek penelitian adalah asli keturunan Minangkabau (dua generasi di atas sampel penelitian), yang kesemuanya itu didapat dari kuisioner penelitian.

Di dalam penelitian ini yang dinilai adalah antropometri sendi pergelangan tangan normal etnis Minangkabau, yang nantinya mempunyai kaitan dengan penilaian dalam manajemen fraktur distal radius untuk mempertahankan keselarasan anatomi setelah reposisi, baik secara open reduction ataupun closed reduction. 8,9

Penelitian mengenai morfometri pada sendi pergelangan tangan, khususnya pada distal radius sudah banyak dilakukan. Bahkan dalam penelitian yang telah ada banyak yang menghubungkan antara morfometri dengan biomekanik dari sendi pergelangan tangan itu sendiri. Seperti pada penelitian yang dilakukan pada 12 kadaver. Dimana di dalam penelitian tersebut menitikberatkan pada konsentrasi tekanan pada distal radius pada posisi palmar tilt $0^{\circ}$, maka beban yang ditimbulkan akan terkonsentrasi pada regio volar dari sendi radiolunatum. Sehingga jika terjadi angulasi ke dorsal hingga $30^{\circ}$ pada permukaan radiolunatum, maka beban yang diterima pergelangan tangan dan distal radius tidak akan banyak menyimpang. ${ }^{46}$

Deskripsi mengenai morfometri dari distal radius seperti dalam referensi OTA (Gartland) banyak diadopsi oleh sebagian besar ahli ortopaedi saat ini, termasuk di indonesia sebagai nilai standar pada evaluasi pada fraktur distal radius. Dalam penelitian ini disebutkan bahwa perubahan palmar tilt dan penurunan radial inclination pada 60 kasus tidak bermakna secara klinis. ${ }^{44}$.

Pada 297 kasus manajemen konservatif pada fraktur distal radius yang di evaluasi dalam jangka panjang, dimana radial inclination berkurang $5^{\circ}$ yang disertai palmar tilt berubah lebih dari $15^{\circ}$ serta ulnar variance berubah lebih dari $5 \mathrm{~mm}$, maka secara klinis hasil yang di harapkan tidak memuaskan. ${ }^{48}$ Sehing- 
ga menyebabkan ketidaksesuaian posisi dari sendi radioulnar distal. Hal tersebut menjadi faktor predisposisi untuk terjadinya perubahan degeneratif dari sendi pergelangan tangan. ${ }^{49}$ Penelitian klinis lain menyatakan bahwa kehilangan nilai palmar tilt sebesar $11^{\circ}-12^{\circ}$ memiliki nilai yang signifikan terhadap fungsi pergelangan tangan di kemudian hari. ${ }^{17}$ Penyimpangan nilai dorsal tilt lebih memiliki nilai terhadap fungsi pergelangan tangan dibanding dengan adanya penyimpangan pada radial deviation, radial shortening, bahkan pada gangguan dari integritas dari radioulnar joint. ${ }^{44}$ Pada penelitian retrospektif disimpulkan bahwa penyimpangan nilai $12^{\circ}$ dari nilai normal palmar tilt menyebabkan terjadinya peningkatan lebih dari $80 \%$ gambaran artritis pada tampilan radiologi serta terdapatnya gangguan fungsi dari pergelangan tangan. ${ }^{17}$

Penyebab berkurangnya fungsi dari pergelangan tangan adalah multifaktorial. Dalam penelitian lain disebutkan bahwa gangguan fungsi tidak akan terjadi sampai terjadi penyimpangan palmar tilt minimal $20^{\circ}$. Angulasi pada distal radius menyebabkan terjadinya carpal malalignment yang berhubungan dengan fungsi dari pergelangan tangan. Perubahan palmar tilt tidak hanya mempengaruhi mekanisme dari radiocarpal joint saja, tetapi juga mempengaruhi mekanisme dari radioulnar joint. Selain itu perubahan pada palmar tilt meningkatkan regangan yang berlebihan pada ligament dorsal radioulnar sehingga menyebabkan terjadinya peningkatan terjadinya rotasi dari lengan bawah. ${ }^{17}$ Radial shortening lebih dari $2 \mathrm{~mm}$ menyebabkan penurunan kemampuan dalam hal kekuatan menggenggam, dan jika pemendekan lebih dari $4 \mathrm{~mm}$ tidak hanya kehilangan dalam kemampuan menggenggam, tapi juga berhubungan dengan nyeri yang berkepanjangan. ${ }^{17}$

Pada penelitian lain disebutkan bahwa pemendekan dari radial lenght akan mempengaruhi pada TFCC (Triangular fibrocartilage complex) yang menyebabkan perubahan besar pada kinematik pergelangan tangan, namun pengaruhnya terhadap radial inclination tidak begitu bermakna, namun dapat menyebabkan penurunan fungsi menggenggam. Jika ditelusuri lebih lanjut perubahan radial inclination dalam jangka panjang akan meningkatkan resiko terjadinya perubahan degeneratif pada sendi lebih dari $90 \% .{ }^{47}$

Dari penelitian ini nilai mean pada radial inclination dan palmar tilt pada wanita lebih besar, namun nilai mean radial lenght pada wanita lebih kecil. Begitu pula nilai mean palmarfleksi lebih besar pada wanita, tetapi pada dorsofleksi, ulnar deviasi, dan radial deviasi lebih besar pada pria. Namun untuk penilaian secara statistik tidak dilakukan pada penelitian ini karena tujuan dari penelitian ini tidak mencari signifikansi antara nilai anatomi (radiologi) dengan nilai kinesiologi dari sendi pergelangan tangan, tapi hanya menilai antropometri sendi pergelangan tangan pria dan wanita mahasiswa kedokteran beretnis Minangkabau sebagai data dasar untuk penelitian selanjutnya.

Di dalam penelitian ini juga, secara statistik terdapat nilai yang signifikan pada radial inclination, dengan derajat kepercayaan $95 \% \quad(p<0,05)$ yaitu terdapat perbedaan nilai rerata yang bermakna pada radial inclination antara pria dan wanita mahasiswa kedokteran beretnis Minangkabau di lingkungan RSUP Dr. M. Djamil Padang Sumatera 
Barat. Secara teori wanita dewasa cenderung lebih pendek dibandingkan dengan pria dewasa dan mempunyai tulang yang lebih kecil dan lebih sedikit massa otot. Wanita lebih banyak mempunyai lemak sub kutan dan mempunyai sudut siku yang lebih luas sehingga gerakan antara lengan bawah dengan lengan atas lebih luas. Begitu pula gangguan fungsi metabolik tubuh, gangguan gizi/ diet, gangguan endokrin akan mempengaruhi struktur tulang ${ }^{29}$. Selain daripada itu awal menarche yang lewat dari seharusnya menyebabkan pertumbuhan tulang akan berlangsung lebih lama sebagai akibat dari epifisis yang belum menutup yang akhirnya tubuh dewasa seseorang menjadi lebih tinggi, sehingga bisa dikatakan umur menarche mempunyai kaitan dengan ukuran tulang. ${ }^{50}$ Sehingga dalam penelitian ini awal menstruasi pada sampel penelitian perlu juga di kaji. Mungkin hal- hal tersebut di atas inilah yang menyebabkan radial inclination pria dan wanita signifikan dalam penelitian ini. Dimana sudut radial inclination pada wanita lebih besar dari pria. Peneliti menganjurkan agar parameter yang didapatkan dari penelitian ini dapat dijadikan sebagai referensi bersama dengan hasil penelitian lain dalam menetapkan nilai rujukan yang sesuai untuk evaluasi setelah reposisi pada fraktur distal radius pada etnis Minangkabau.

Penelitian yang dilakukan di Jakarta menemukan perbedaan yang signifikan antara pria dan wanita pada parameter radial inclination, palmar tilt dan radial lenght (200 sampel). ${ }^{9}$ Penelitian di Malaysia mendapatkan radial inclination dan palmar tilt antara pria dan wanita tidak bermakna secara statistik (64 sampel). ${ }^{11}$
Selain dari morfometri sendi pergelangan tangan, yang tidak kalah penting dalam penilaian keselarasan anatomi dan fungsi dari sendi pergelangan tangan adalah Range of Motion atau rentang gerak sendi. ${ }^{6}$ Sehingga pemeriksaan rentang gerak sendi juga merupakan bagian yang tidak terpisahkan dari penilaian evaluasi setelah tindakan reposisi pada fraktur distal radius. Dari nilai referensi yang $\mathrm{ada}^{45}$, memang didapatkan nilai yang berbeda dibanding dalam penelitian ini. Sehingga parameter ROM pada penelitian ini sebaiknya juga dipakai dalam evaluasi penilaian fungsi pergelangan tangan setelah tindakan reposisi pada fraktur distal radius pada etnis Minangkabau, walaupun belum teruji secara statistik.

Berdasarkan pada fakta penelitian di atas dapat disimpulkan bahwa sangatlah penting untuk mengembalikan kesegarisan anatomi sendi pergelangan tangan ke nilai normal. Sehingga pasien dapat mengerjakan aktifitas seperti sediakala sesuai waktu yang diharapkan, mengembalikan kekuatan menggenggam, serta menghindari resiko degeneratif di kemudian hari. ${ }^{7}$

Hingga saat ini, SMF bedah ortopaedi RSUP Dr. M.Djamil padang menilai akseptibiltas setelah reposisi fraktur distal radius masih menggunakan parameter dari kepustakaan barat, padahal pasienpasien tersebut beretnis Minangkabau. Penilaian dan evaluasi setelah tindakan seharusnya menggunakan parameter yang sesuai dengan karekteristik anatomis pasien. Penelitian ini menunjukkan parameter anatomi etnis minangkabau berbeda dengan parameter yang dilaporkan oleh kepustakaan barat yang dijadikan rujukan selama ini. 
Tabel 4 : Perbandingan Morfometri pergelangan tangan hasil penelitian dengan nilai referensi

\begin{tabular}{lcc}
\hline \multicolumn{1}{c}{ Pemeriksaan } & Hasil pada penelitian ini & Nilai referensi \\
\hline & & \\
Palmar fleksi & $79.22 \pm 9.58^{\circ}$ & $70^{\circ}-90^{\circ * *}$ \\
Dorso fleksi & $72.22 \pm 10.54^{\circ}$ & $65^{\circ}-85^{\circ * *}$ \\
Ulnar deviasi & $40.74 \pm 9.43^{\circ}$ & $25^{\circ}-40^{\circ *}$ \\
Radial deviasi & $24.68 \pm 4.92^{\circ}$ & $15^{\circ}-25^{\circ *}$ \\
Radial inclination & $24.02 \pm 3.49^{\circ}$ & $13^{\circ}-30^{\circ *}$ \\
Radial lenght & $11.35 \pm 1.56 \mathrm{~mm}$ & $11 \mathrm{~mm}-13 \mathrm{~mm}^{*}$ \\
Palmar tilt & $12.27 \pm 6.12^{\circ}$ & $10^{\circ}-21^{\circ}$ \\
\hline
\end{tabular}

Perbandingan Morfometri pergelangan tangan dalam penelitian ini dengan nilai referensi dari Orthopaedic Trauma Association ( OTA ) ( Gartland et al, 1951)*(44) dan untuk Range Of Motion (ROM) dari Manual of Structural Kinesiology The wrist and Hand Joints ( R.T. Floyd, Ed.D, ATC, CSCS ) ${ }^{\star *}(45)$

\section{SIMPULAN}

Didapatkan nilai rata-rata dan simpangan baku ukuran antropometri sendi pergelangan tangan mahasiswa kedokteran yang beretnis Minangkabau di lingkungan RSUP Dr. M. Djamil Padang Sumatera Barat.

\section{DAFTAR PUSTAKA}

1. Will K. Kewarganegaraan Multikultural. Jakarta: LP3ES; 2003.

2. Glinka J, Artaria, Koesbardiati T. Metode Pengukuran Manusia. Surabaya: Airlangga University Press; 2008.

3. Wignjosoebroto S. Ergonomi Studi Gerak dan Waktu. Surabaya: Gunawidya; 2008.

4. Aryanta W. Antropometri Radiologis Sendi Lutut Pada Manusia Dewasa pada Etnis Sunda di Rumah Sakit Hasan Sadikin Bandung. Bandung: Fakultas Kedokteran Universitas Pa-djajaran; 2008.

5. Nagar M, Bhardwaj R, Prakash R. Anterversion in Adult Indian Femora. J Anat Soc India. 2000; 49: 9-12.

6. Wilcke M. Fracture of The Distal Radius: Epidemiology, Treatment, and Outcome Assessment. Stockhlom: Karolinska Institute; 2013.
Terdapat perbedaan bermakna secara statistik antara nilai radial inclination antara pria dan wanita mahasiswa kedokteran yang beretnis Minangkabau di Padang Sumatera Barat. Tampak perbedaan nilai ukuran antropometri antara penelitian ini dengan kepustakaan yang lazim.

7. Burhan E, Manjas M, Riza A, dkk. Perbandingan Fungsi Extrimitas Atas Pada Fraktur Metafise Distal Radius Intraartikuler Usia Muda Antara Tindakan Operatif dan Non Operatif Dengan Penilaian Klinis Quickdash Score; 2014

8. Smeltze SC, Bare BG, Hinkle JL. Brunner \& Suddarth Textbook of Medical Surgical. 11th ed. Philadelpia: Lippincot William \& Wilkins; 2008.

9. Wijiono, Syaiful. Distal Radius Morphometry of Indonesian Population. Med J Indones. 2013;22(03)173-7.

10. Nana $A D$, Joshi $A$, Lichtman DM. Plating of the Distal Radius. J Am Acad Orthop Surg. 2005;337:159-71

11. Chan CYW, Vivex AS, Leong WH, et al. Distal Radius Morphometry in The Malaysian Population. Malays Orthop J. 2008;2(2):2730.

12. Prithiskumar IJ, Francis DV, Nithya-nand M, et al. Morfometry of Distal Radius: an 
Osteometric Study in The Indian Population. IJBAMR. 2012;-1(3):166-71.

13. Terry C, James HB. Campbell's Operative Orthopaedics. 8th ed.; Elsevier; 2007.

14. Graham TJ. Surgical Correction of Malunited Fractures of The Distal Radius. J Am Acad Orthop Surg. 1997;-5:270.

15. Robert RS, Scott CS, Steven JK. Emergency Orthopaedics. The Extrimities. 5th ed; 2007.

16. John GS. American Society For Surgery of The Hand: Essentials of Hand Surgery. 1st ed. Philadelpia: Lippincot William \& Wilkins; 2002

17. Robert WB, James DH, Charles CB. Rockwood and Green's Fractures in Adults. 6th ed. Philadelpia: Lippincot William \& Wilkins. 2006.

18. Greene WB. Netter's Orthopaedics. 1st ed. Elsevier; 2001.

19. Mark D. Orthopaedics Examination, Evaluation, and Intervention. 2nd ed. Allegheny General Hospital, 2002

20. Sandjaja G. Gambaran Nilai Rata-rata Aksis Sudut Radius Distal Normal Pada Pengunjung di RSCM. Universi-tas Indonesia: Mount Pleasant; 1993.

21. Kroemer and Elbert. Engineering Physiology: Bases of Human Factor/ Ergonomic. 3rd ed. America: An International Thomson; 2007.

22. Britannica Online Dictionary (Diunduh 2014 Des 05). Tersedia dari: http://www.Britannica .com/eb/article-9007796/anthropometry.

23. Merriam Webster Online Dictionary (Diunduh 2014 Des 05). Tersedia dari:http//www.Medical-dictionary,

Thefreedictionary.com/anthropometry

24. Yochum TR, Rowe LJ. Essentials of Skeletal Radiologi. 2nd ed. Philadelpia: Lippincot William \& Wilkins; 1996.

25. Antropometri (Diunduh 29 Okt 2014). Tersedia dari: https://bambangwisanggeni.wordpress.com/2010/03/02/antro pometri/.

26. Irfan M, Wismanto, Meidian AC. Pengukuran Lingkup Gerak Sendi Pergelangan Tangan dan Tangan (Wrist Joint and Hand). Universitas Esa Unggul.;2013.

27. Hardyal S. How to Record Geniometric Measurement (Diunduh 2014 Des 04). Tersedia dari: http//www.ehow.com

28. Pudjiastuti SS, Utomo B. Fisioterapi Pada Lansia. Jakarta: EGC; 2003.
29. Snell RS. Anatomi Klinik Untuk Mahasiswa Kedokteran. 3rd ed. Jakarta: EGC; 2006.

30. Knight B. Simson's Forensic Medicine: Identification of the Living and Dead. New York: Oxford University Pres; 1997.

31. Sloane E. Anatomi dan Fisiologi untuk Pemula. Jakarta: EGC; 2004.

32. Parker S. Eyewitness-Kerangka. Jakarta: PT. Bentara Antar Asia; 1992.

33. Rasjad C. Pengantar IImu Bedah Ortopedi. Jakarta: PT. Yarsif Wantam-pone; 2007.

34. Snell RS. Anatomi Klinik Untuk Mahasiswa Kedokteran. 3rd ed. Jakarta: EGC; 2006.

35. Byers SN. Introduction to Forensic Anthropology: Basics of Human Osteo-logy and Odontology. 3rd ed. Boston; 2008.

36. Knight B. Forensic Pathology: The Establishment of Identity of Human Remains. 2nd ed. New York: Oxford University Press; 1996.

37. Tjandra H. Osteoporosis. Jakarta: PT. Gramedia; 2009.

38. Rebecca A, Loredo SDG, Garcia G. Radiographic Evaluation of The Wrist: A Vanishing Art, Seminars in Roentgenology. Elsevier; 2005.

39. Sudigdo S, Sofyan I. Dasar-dasar Metodologi Penelitian Klinis. 2nd ed. Jakarta: Sagung Seto; 2002.

40. Navis, A. A. (1984). Alam Terkembang Jadi Guru: Adat dan Kebudayaan Minangkabau. Jakarta: Grafiti Pers.

41. Whitley AS, Sloane c, Hoadley A, et al. Clark Positioning in Radiography. 12th ed. London; 2005.

42. Philip WB. Atlas Radiographic Position and Radiologic Procedures. 8th ed. Ohio: The Ohio State University; 1995.

43. Hollevoet N, Van MG, Van SP, et al. Comparison of Palmar Tilt, Radial Inclination and Ulnar Variance In right and Left Wrist. J Hand Surg Br. 2000; 25(5): 431-03.

44. Gartland JJ, werley CW. Evaluation of healed colles' fractures. J Bone Joint Surg Am. 1951;33A(4):895-907

45. R.T.Floyd, Ed.D, Clem W. Thompson ATC, CSCS. The wrist and Hand Joints: Manual of Structural Kinesiology. Mc Graw Hill, Chapter $715^{\text {th }}$ Edition

46. Miyake $T$,Hashizume $H$, Inoue $H$, Shi $Q$, Nagayama N. Malunited colles fracture, 
analysis of stress disttibution. J Hand Surg $\mathrm{Br}$. 1994;19(6):737-42

47. Adams BD. Effects of radial deformity on distal radioulnar joint mechanics. J Hand Surg Am. 1993;18:492-8

48. Altissimi M, Attenucci R, Fiacca C. Long term result of conservative treatment of fractures of distal radius. Clin Orthop Relat Res. 1986;206:202-10
49. Downing ND, Karantana A. Aspects of current management: a revolution in the management of ftctures of the distal radius. $J$ Bone Joint Surg $\mathrm{Br}$. 2008;90(10);1271 -5

50. Onland-Moret NC, Peeters PHM, Van Gils $\mathrm{CH}$, Clavel-Chapelon $\mathrm{F}$ et all. Age at Menarche in Relation to Adult Height. Am J Epidemiol 2005;162(7): 623-32 